\title{
Chemical and Structural Analysis of Rocks Using X-ray Fluorescence and X-ray Diffraction Techniques
}

\author{
Mohammed M. Sabri \\ Department of Physics, Faculty of Science and Health, Koya University, Koya KOY45, Kurdistan Region - F.R. Iraq
}

\begin{abstract}
Rock examinations for mining and commercial use are a vital process to save money and time. A variety of methods and approaches have been used to analyze rocks and among them, X-ray fluorescence (XRF), and X-ray diffraction (XRD) techniques proved to be an accurate method. This research was conducted to evaluate the utility and reliability of XRF and XRD to analyze the major and trace elements of rocks as well as their crystalline structures. Results showed that XRF and XRD techniques are fast and reliable, nondestructive and non-invasive analytical tools for mineral analysis, particularly for rocks. For this purpose, the analysis of 28 samples of rocks, which collected from three different places of Kurdistan region-Iraq, is reported. These places are Haybat Sultan (HS) region in Koya city as well as TaqTaq (TA) and Garmuk (GT) district nearby Koya city. Throughout this analysis, 34 major and trace elements were detected in the rocks collected from HS region, whereas forty major and trace elements were detected in the rocks collected from TA district and GT district. In addition, it was found that the structures of these rocks were crystalline in nature. This was proved through the value of diffracted angle and it was found that the majority of these rocks are oxides. The external view (the appearance) of all collected rocks was also discussed and it was found that each rock consists of a variety of minerals which will be the reason that each rock has a specific color.
\end{abstract}

Index Terms-Minerals, Rocks, X-ray diffraction, X-ray fluorescence.

\section{INTRODUCTION}

There are a variety of materials available in nature such as rock, soil, oil (some places in the world), and water. Exploring these materials is a matter of interest due to their importance impacts and possible significant applications. Among these materials, rocks with their different types have attracted a special interest by researchers, as the evaluation of the source of the rock is considered as an important task for the purpose

ARO-The Scientific Journal of Koya University

Vol. VIII, No.1 (2020), Article ID: ARO.10643, 9 pages

DOI: $10.14500 /$ aro. 10643

Received: 09 March 2020; Accepted: 12 June 2020

Regular research paper: Published 17 June 2020

Corresponding author's e-mail: mohammed.mohammedsabri@

koyauniversity.org

Copyright (C) 2020 Mohammed M. Sabri. This is an open-access

article distributed under the Creative Commons Attribution

License. of oil exploration (Mirza et al., 2017; Fatah and Mohialdeen, 2016; Mohialdeen, Hakimi and Al-Beyati, 2015; Tissot and Welte, 1984). In addition, rocks' investigation could be used in the assessment of the source of the rock, such as measuring the level of maturity, the types of organic materials content of the rock as well as to define the paleoenvironmental conditions (Hunt, 1996). Comparing to other regions around the world, Kurdistan region of Iraq is a rich region full of various types of materials such as those mentioned above and especially rocks (Hassan et al., 2015). These regions include, for example, mountains and the regions nearby it. However, limited studies have been conducted in the concern of this matter. It has been demonstrated that to build a clear view of the characteristics of the sediment's source area, the composition of the rocks should be investigated (Roser and Korsch, 1988) and to do so, trace elements are extremely important (Lopez et al., 2005). In fact, there are three types of rocks, which are being formed (and destroyed). Earth's first rocks were igneous rocks. These form from molten rock that has cooled and hardened. Second, sedimentary rocks are formed from the shells and skeletons of microscopic sea creatures. Finally, metamorphic rock forms when rocks are squeezed and heated deep under the earth's crust.

It is important to mention that X-ray fluorescence (XRF) technique has become one of the major instruments in diagnostics (Meenaa et al., 2018; Sarrazin et al., 1998; Vaniman et al., 1998; Vaniman, Bish and Chipera, 1991) due to its ability to analyze the chemistry of the sample (Sanchez et al., 2008; Nayak and Singh, 2007). Besides to XRF (Cornaby et al., 2001), X-ray diffraction (XRD) technique (Wadsworth and Baird, 1989) is also considered to be the most conclusive technique to investigate the phase composition (Mohammed, 2012) of the matter, particularly rocks (Marinangeli et al., 2015; Cornaby et al., 2001; Vaniman et al., 1998; Vaniman, Bish and Chipera, 1991). Each phase (metal or metal oxide) has its own unique diffraction spectrum and therefore, it is possible to distinguish between compounds, as this technique is sensitive to crystal structure rather than to composition (Loubser and Verryn, 2008; Sanchez et al., 2008). XRD has its own importance in rocks investigation, as this technique has the ability to identify the structure of rocks in terms of crystallinity or amorphousness. Dealing with the rocks and investigating their chemical and crystalline structures are of 
considerable problem that should be taken into consideration due to the impact of rocks' applications in various field such as in industry and particularly in cement industry. Moreover, the existence of metal and/or metal oxide in these rocks is of importance matter due to the possible future applications in a variety of fields such as in electricity. The main aim for conducting this research is to further go inside rocks and analyze their structures, both chemically and structurally.

\section{EXPerimental Details}

The experimental process starts with collecting the rock samples from several Kurdistan region of Iraq, then grinding the samples and finally analyzing the rocks using XRF and XRD techniques.

\section{A. Samples (Rocks) Collecting}

The rocks that used in this research have been collected from three different places of Kurdistan region of Iraq. Ten of these samples codes of HS1-HS10 were collected from Haybat Sultan (HS) in Koya city and the other ten samples were collected from TaqTaq (TA) codes of TA1-TA10 that located close to Koya city and finally eight samples codes of GT-1-GT8 were collected from Garmuk (GT), which is also related to TA region.

\section{B. Samples (Rocks) Grinding}

The bulk of these rocks was then grinded using Mini mill II ball machine of type Malvern Panalytical, Gurgaon (Panalytical India) to obtain a fine powder.

\section{Rocks Analysis}

In this paper, the collected rocks were chemically and structurally analyzed using both XRF and XRD techniques as discussed in details in below sections.

\section{XRF Technique}

The elemental concentration and their emitted energies in $\mathrm{KeV}$ for all collected rocks were determined using energy dispersive XRF (EDXRF). All measurements were carried out under vacuum using a Rigaku NEX CG with RX9, Mo, $\mathrm{Cu}$, and $\mathrm{Al}$ targets. Chemical elements of high and low concentration were detected within our collected rocks. The EDXRF $\mathrm{K}^{\alpha}$ and $\mathrm{K}^{\beta}$ lines intensities were measured for all rocks' elements, in which the applied voltage increased in general with the required lines energies. The X-ray measuring time was $200 \mathrm{~s}$ for the $\mathrm{Al}$ target, whereas was $100 \mathrm{~s}$ for the other targets. Furthermore, X-rays from the $\mathrm{X}$-ray tube pass through an optional filter on their way to the rocks sample. The sample placed in the chamber and measured by $20 \mathrm{~mm}$ diaphragm in vacuum. The X-rays are then transport from the sample to the detector which is electrically cooled. The signal is then processed by electronics and sent to a computer program, where the chemical compositions and intensity versus energy is measured (Abdullah, Chaqmaqchee and Anwer, 2017; Chaqmaqchee and Baker, 2016). A schematic diagram of the typical EDXRF is shown in Fig. 1.

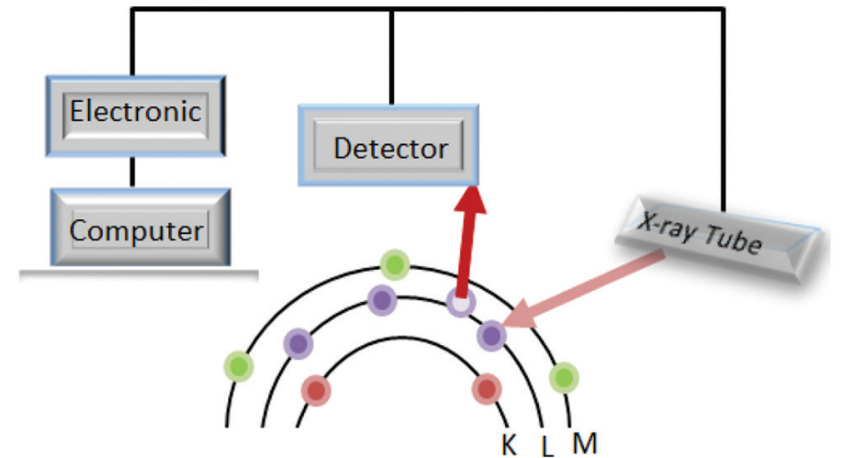

Fig. 1. A schematic of a typical energy dispersive X-ray fluorescence spectrometer.

\section{$X R D$ technique}

The crystalline structures of the rocks were analyzed using a high-resolution X-ray powder diffraction technique of type Panalytical Empyrean with $\mathrm{CuK}^{\alpha}$ radiation of the wavelength $(\lambda)$ of $0.15406 \mathrm{~nm}$. The voltage and the current that used throughout the analysis were $45 \mathrm{kV}$ and $40 \mathrm{~mA}$, respectively (Faraj, Kaka and Omar, 2019; Faraj, Chaqmaqchee and Omar, 2017). The XRD (JCPDS card No. 03-1005) data revealed that all the collected rock samples are crystalline in nature.

\section{RESULTS AND DISCUSSION}

This section has been divided into three sub-sections of XRF, $\mathrm{XRD}$, and the analysis of rocks appearance.

\section{A. $X R F$}

Rigaku NEX CG XRF spectrometer analyses were used to determine the elements of the collected rocks. When these samples are irradiated with X-rays, the intensity as a function of energy can be calculated over the energy range of $1-20 \mathrm{keV}$ at the same computing conditions. Fig. 2 shows the peaks in the ranges of $1.74,2.32,3.69,4.03$, $5.89,6.4,14.19,16.83$, and $17.48 \mathrm{keV}$ corresponding to $\mathrm{Si}-\mathrm{k}^{\alpha}, \mathrm{S}-\mathrm{k}^{\alpha}, \mathrm{Ca}-\mathrm{k}^{\alpha}, \mathrm{Ca}-\mathrm{k}^{\beta}, \mathrm{Mn}-\mathrm{k}^{\alpha}, \mathrm{Fe}-\mathrm{k}^{\alpha}, \mathrm{Sr}-\mathrm{k}^{\alpha}, \mathrm{Nb}-\mathrm{k}^{\alpha}$, and Mo- $\mathrm{k}^{\alpha}$ lines. It can be seen from Fig. 2a that the intensity of $\mathrm{Ca}-\mathrm{k}^{\alpha}$ for all HS samples has higher intensity (high $\mathrm{Ca}$ concentration) compared to other rocks samples of TA and GT (Figs. 2b and c), whereas the intensity of S-k ${ }^{\alpha}, S r-k^{\alpha}$, $M n-\mathrm{k}^{\alpha}$, and $M o-\mathrm{k}^{\alpha}$ is low or almost negligible. In addition, the intensity of $\mathrm{Fe}-\mathrm{k}^{\alpha}$ is high (high Fe concentration) in the rocks labeled HS4, HS5, TA1, TA4, TA5, TA9, TA10, and GT7, as shown in Fig. 2. Rocks are divided into two classes according to whether they contain a greater proportion of iron and magnesium or of potassium, sodium, and calcium. Igneous rocks which contain a high percentage of iron and magnesium (ferromagnesian silicates) tend to possess a dark color and are said to be of basaltic or mafic composition. Because of their iron content, such rocks tend to be both denser and darker in color than those rocks composed mainly of non-ferromagnetic silicates. In contrast, igneous rocks 

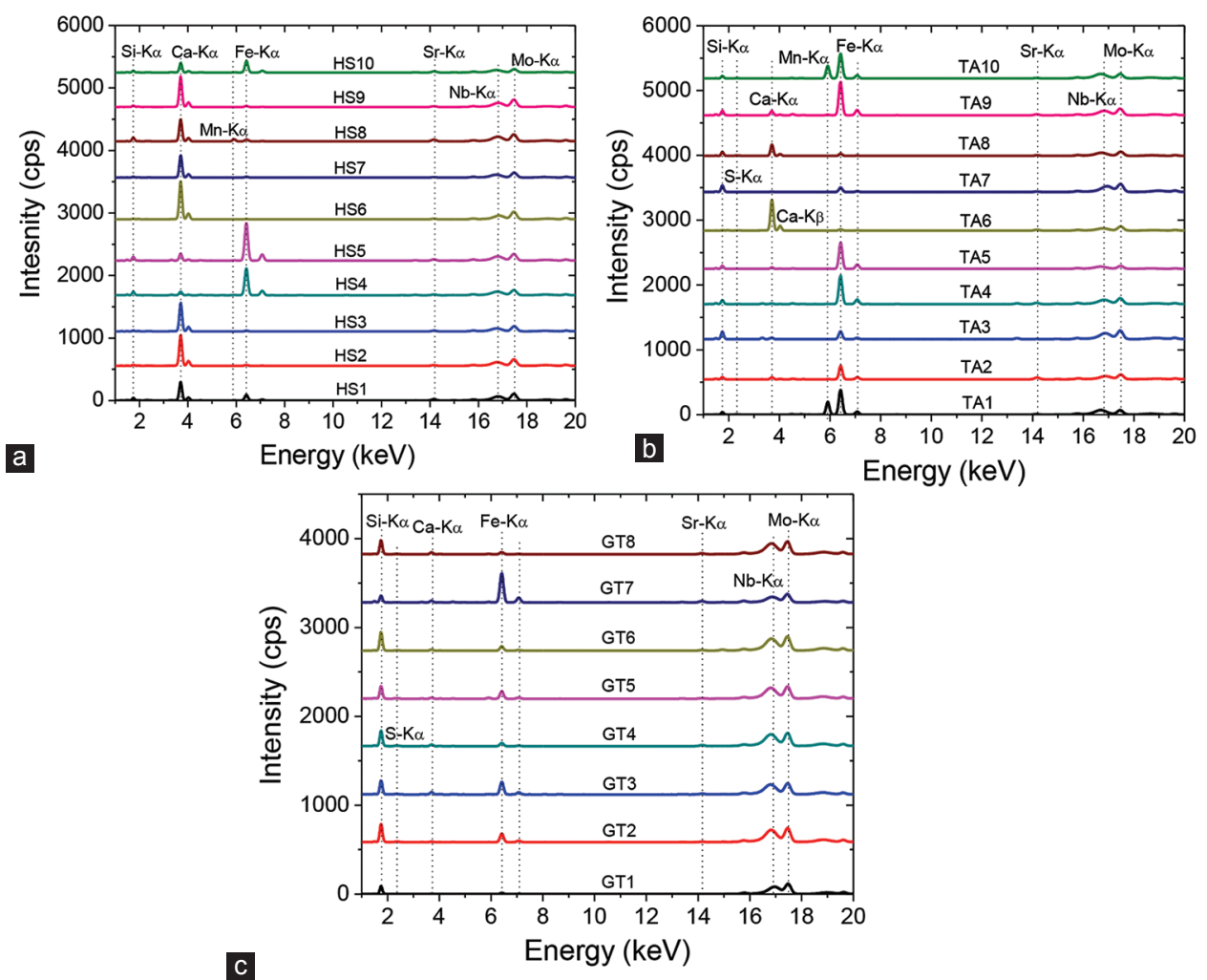

Fig. 2. Intensity versus energy for various rocks of (a) Haybat Sultan, (b) TaqTaq, and (c) Garmuk calculated over the energy range from 1 to 20 keV using X-ray fluorescence with $\mathrm{RX} 9, \mathrm{Mo}, \mathrm{Cu}$, and $\mathrm{Al}$ targets.

which contain a greater percentage of potassium, sodium, or calcium (non-ferromagnetic silicates) tend to have a lighter color and are said to be of granitic or felsic composition. Such rocks tend to contain a relatively greater percentage of silica $\left(\mathrm{SiO}_{2}\right)$; typically, this is about $70 \%$ by mass. Some minerals are always of the same color, as a consequence of their chemical composition and structure. Their color is a useful aid to identification. Other minerals, such as fluorite, can be different colors due to tiny amounts of chemical impurities, structural flaws, or to their different habits.

Rock types can be classified in terms of chemistry, how the form and environment of formation. Some structures, such as bedding, igneous layering, and gneissic banding, are formed at the same time as the rock itself, but others, such as folding and shearing (stretching of mineral grains), occur later. Many structures exist over a vast range of scale, for example, folding can be seen in microscopic crystal grains as well as across entire cliff faces.

Color is also useful property in rock identification. It can be used to tell apart different varieties of a rock, and it can also provide information on the composition of the rock. In many cases, the color of a rock will be affected by weathering, so a fresh surface should always be exposed.

The ten rock samples collected from HS region have been experienced a geochemical analysis, along with the ten rock samples collected from TA region and the eight rock samples collected from GT region. The raw and processed data are listed in three tables related to the three different places where the rock sample was collected. These tables are labeled as Table I for HS rock samples, Table II for TA rock samples and finally Table III for GT rock samples.

\section{B. XRD}

For the purpose of analyzing the crystalline structure of the rocks, XRD technique was used. This technique has been used to analyze the mineralogical composition of the powder materials as well as the phase analysis of the multiphase mixtures. From the values of $d$-spacing as well as the values of $2 \theta$, it can be confirmed that the possible minerals of the rock samples could be quartz, alumina, hematite, tridymite, illite and kaolinite, and few other minerals, which is in consistent with Mohammed, 2012; Nayak and Singh, 2007. The main peaks of the XRD data of all rocks are related to $\mathrm{Ca}$-oxide and $\mathrm{Fe}$-oxide such as in HS and TA rocks, whereas they related to silica and Fe-oxide in GT rocks. In addition, alumina $\left(\mathrm{Al}_{2} \mathrm{O}_{3}\right)$ is also a major trace in all the three rock samples of HS, TA, and GT. These are in consistent with the XRF data. For example, the main peak of HS1 rock (Fig. 3a) at about $29.6286^{\circ}$ can be assigned to diffraction of the (220) plane, which could be for iron oxide. In addition, the XRD pattern of TA rocks exhibits a main plane at about $29.1086^{\circ}$, which are corresponding $(h k l)$ to the (100) plane, as shown in Fig. 4h. Finally, the XRD spectrum of GT rock shows a peak at about $26.4306^{\circ}$, which corresponding to (111) plane of crystalline phase of silica (quartz), as shown in Fig. 5a. The crystallinity of the collected rock samples from the three different places of HS, TA, and GT are proven in the XRD data, as shown in Figs. 3-5. These figures show the similarity 
TABLE I

X-ray Fluorescence Measurements for Elements in the Haybat Sultan Rock Samples as Percentages, where the Totals $100 \% \pm 0.05$ Statistical

ERRORS

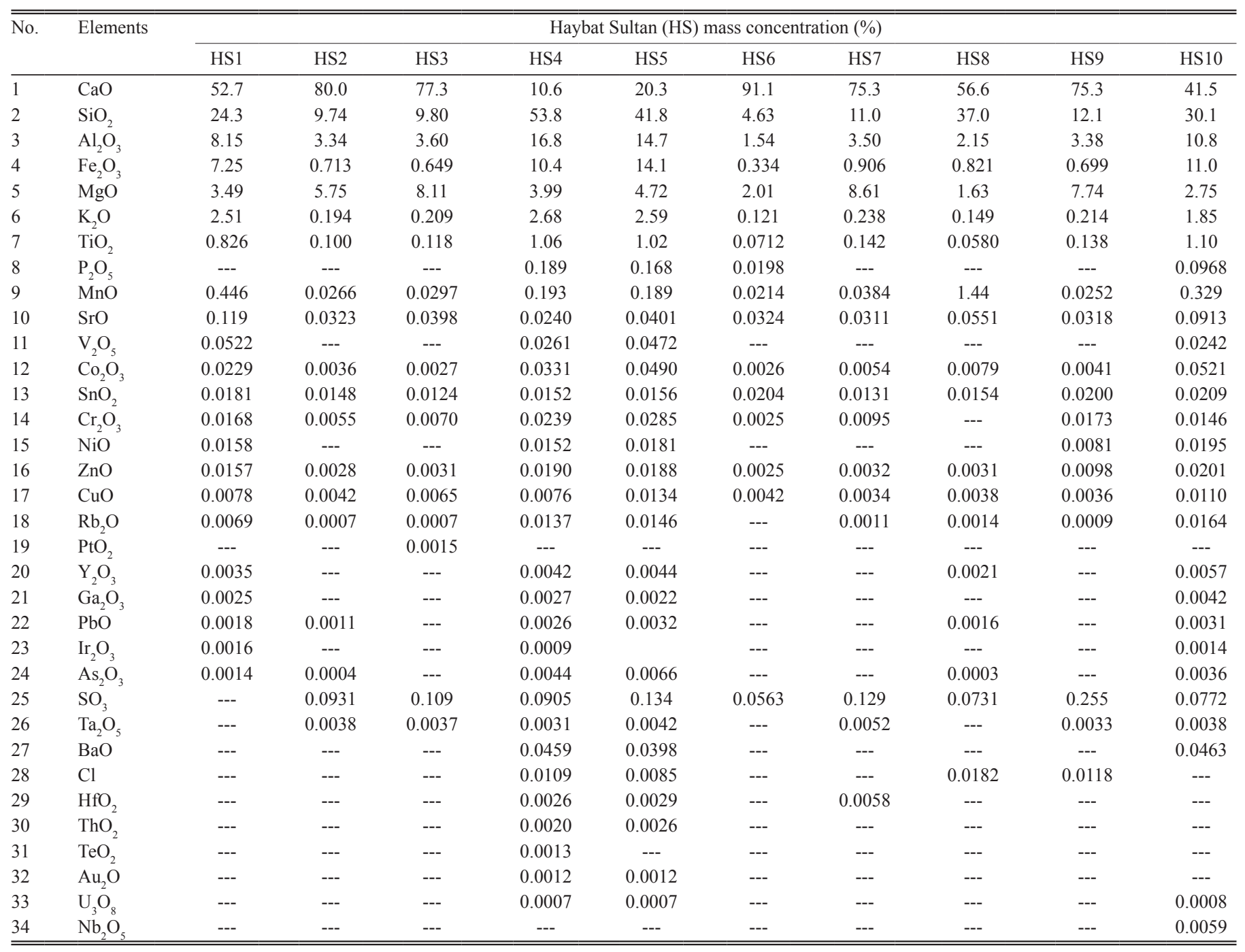

TABLE II

X-ray Fluorescence Measurements for Elements in the TaTaq Rock Samples as Percentages, where the Totals $100 \% \pm 0.05$ Statistical Errors

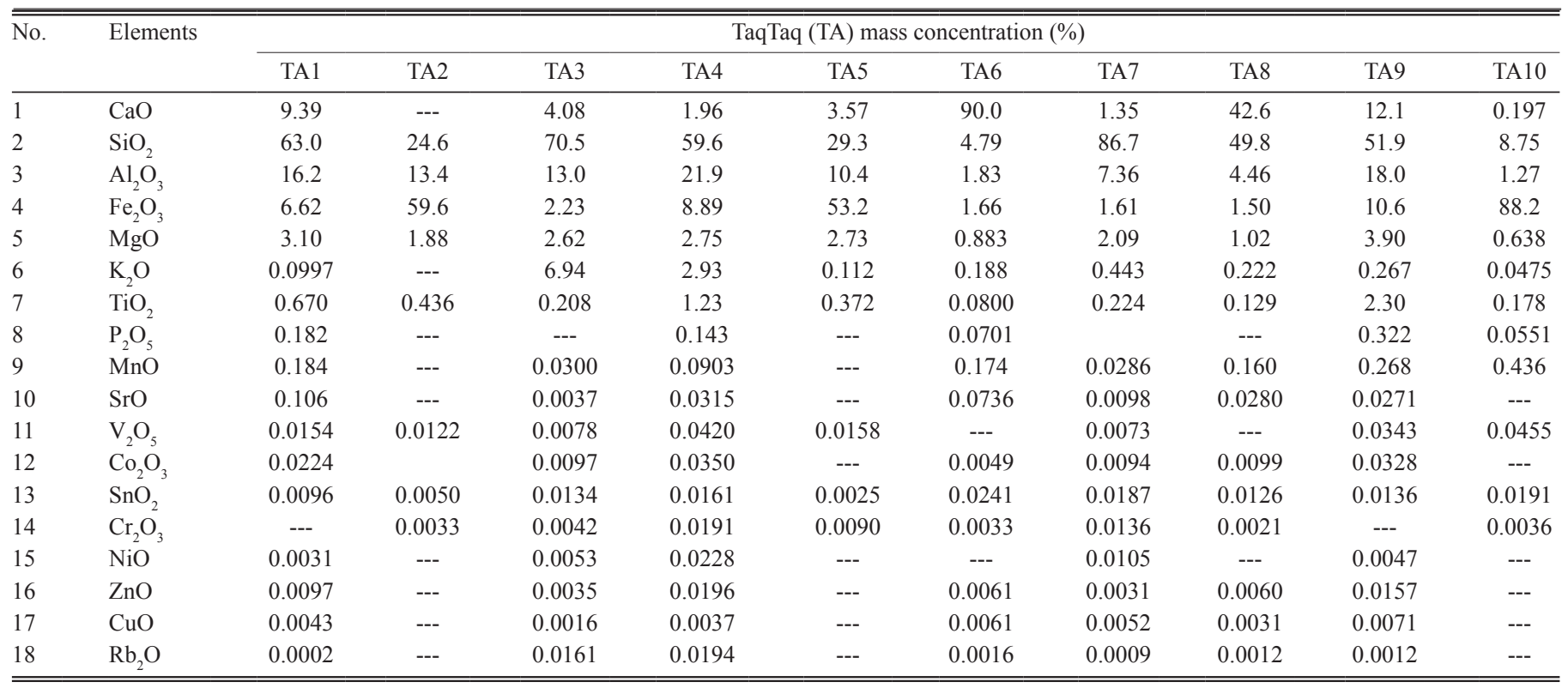


TABLE II

CONTINUED

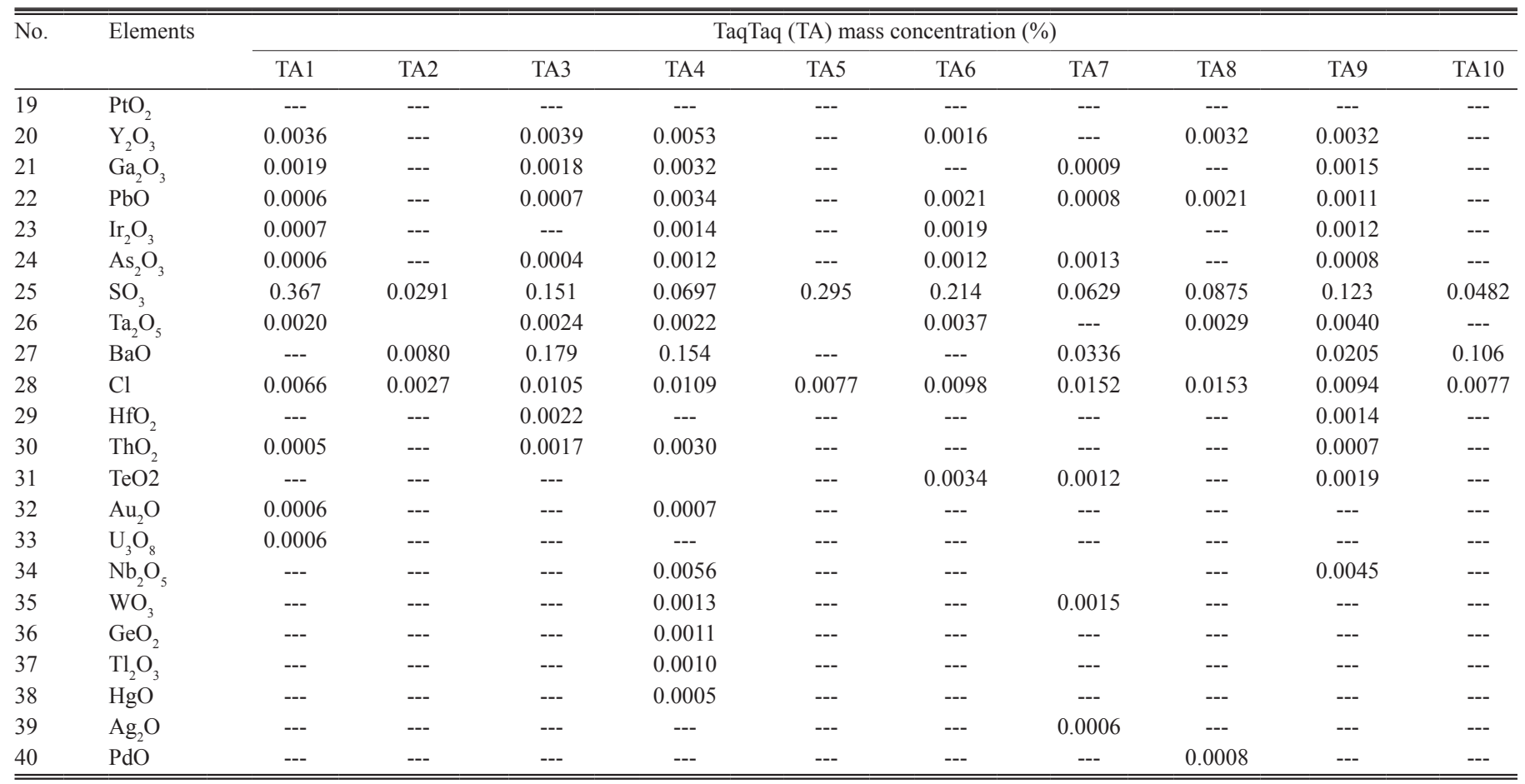

TABLE III

X-ray Fluorescence Measurements for Elements in the Garmuk Rock Samples as Percentages, where the Totals $100 \% \pm 0.05$ Statistical Errors

\begin{tabular}{|c|c|c|c|c|c|c|c|c|c|}
\hline \multirow[t]{2}{*}{ No. } & \multirow[t]{2}{*}{ Elements } & \multicolumn{8}{|c|}{ "Garmuk (GT) Mass Concentration (\%) } \\
\hline & & GT1 & GT2 & GT3 & GT4 & GT5 & GT6 & GT7 & GT8 \\
\hline 1 & $\mathrm{CaO}$ & 1.53 & 1.13 & 5.58 & 4.17 & 2.62 & 2.36 & 4.27 & 5.41 \\
\hline 2 & $\mathrm{SiO}_{2}$ & 94.5 & 92.8 & 85.6 & 88.8 & 86.4 & 93.8 & 65.1 & 89.1 \\
\hline 3 & $\mathrm{Al}_{2} \mathrm{O}_{3}$ & 2.40 & 3.52 & 4.76 & 4.72 & 6.74 & 2.36 & 17.9 & 3.55 \\
\hline 4 & $\mathrm{Fe}_{2} \mathrm{O}_{3}$ & 0.359 & 1.26 & 2.14 & 0.493 & 1.36 & 0.658 & 7.12 & 0.365 \\
\hline 5 & $\mathrm{MgO}^{2}$ & 0.762 & 0.873 & 1.07 & 1.24 & 1.70 & 0.426 & 2.35 & 0.886 \\
\hline 8 & $\mathrm{P}_{2} \mathrm{O}_{5}^{2}$ & --- & --- & --- & --- & --- & --- & 0.226 & --- \\
\hline 9 & $\mathrm{MnO}$ & 0.0110 & 0.0128 & 0.0549 & 0.0114 & 0.249 & 0.0086 & 0.155 & 0.0977 \\
\hline 10 & $\mathrm{SrO}$ & --- & 0.0035 & 0.0091 & 0.0087 & 0.0057 & 0.0054 & 0.0251 & 0.0083 \\
\hline 11 & $\mathrm{~V}_{2} \mathrm{O}_{5}$ & --- & 0.0044 & 0.0057 & --- & 0.0095 & 0.0033 & 0.0331 & --- \\
\hline 12 & $\mathrm{Co}_{2} \mathrm{O}_{3}$ & 0.0020 & 0.0083 & 0.0116 & 0.0029 & 0.0093 & 0.0044 & 0.0330 & 0.0031 \\
\hline 13 & $\mathrm{SnO}_{2}$ & 0.0223 & 0.0091 & 0.0097 & 0.0097 & 0.0103 & 0.0098 & 0.0125 & 0.0115 \\
\hline 18 & $\mathrm{Rb}_{2} \mathrm{O}$ & --- & 0.0005 & 0.0020 & 0.0004 & 0.0022 & 0.0007 & 0.0066 & 0.0005 \\
\hline 19 & $\mathrm{PtO}_{2}$ & --- & --- & --- & --- & --- & --- & --- & --- \\
\hline 20 & $\mathrm{Y}_{2} \mathrm{O}_{3}$ & --- & 0.0015 & 0.0017 & --- & 0.0010 & 0.0080 & 0.0044 & 0.0011 \\
\hline 21 & $\mathrm{Ga}_{2} \mathrm{O}_{3}$ & --- & 0.0004 & 0.0005 & --- & 0.0006 & 0.0002 & 0.0034 & 0.0004 \\
\hline 22 & $\mathrm{PbO}$ & --- & 0.0006 & 0.0007 & 0.0005 & 0.0007 & 0.0005 & 0.0046 & 0.0025 \\
\hline 23 & $\mathrm{Ir}_{2} \mathrm{O}_{3}$ & --- & --- & --- & --- & --- & --- & --- & --- \\
\hline 24 & $\mathrm{As}_{2} \mathrm{O}_{3}$ & --- & 0.0010 & --- & --- & 0.0001 & 0.0003 & 0.0006 & 0.0007 \\
\hline 25 & $\mathrm{SO}_{3}$ & 0.141 & 0.0502 & 0.136 & 0.0480 & 0.0722 & 0.0624 & 0.0532 & 0.176 \\
\hline 26 & $\mathrm{Ta}_{2} \mathrm{O}_{5}$ & 0.0017 & --- & 0.0016 & 0.0011 & 0.0017 & 0.0008 & 0.0033 & 0.0007 \\
\hline 27 & $\mathrm{BaO}$ & --- & --- & 0.0160 & 0.0268 & --- & 0.0164 & 0.0603 & 0.0662 \\
\hline 28 & $\mathrm{Cl}$ & 0.0271 & 0.0144 & 0.0181 & 0.0110 & 0.0206 & 0.0055 & 0.0096 & 0.0261 \\
\hline
\end{tabular}


TABLE III

CONTINUED

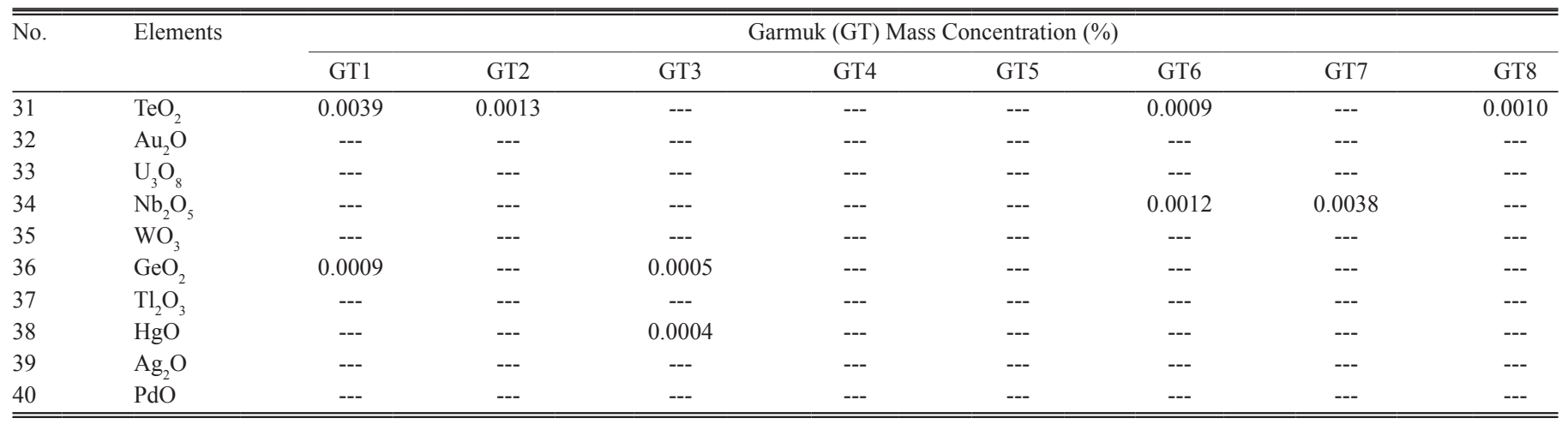
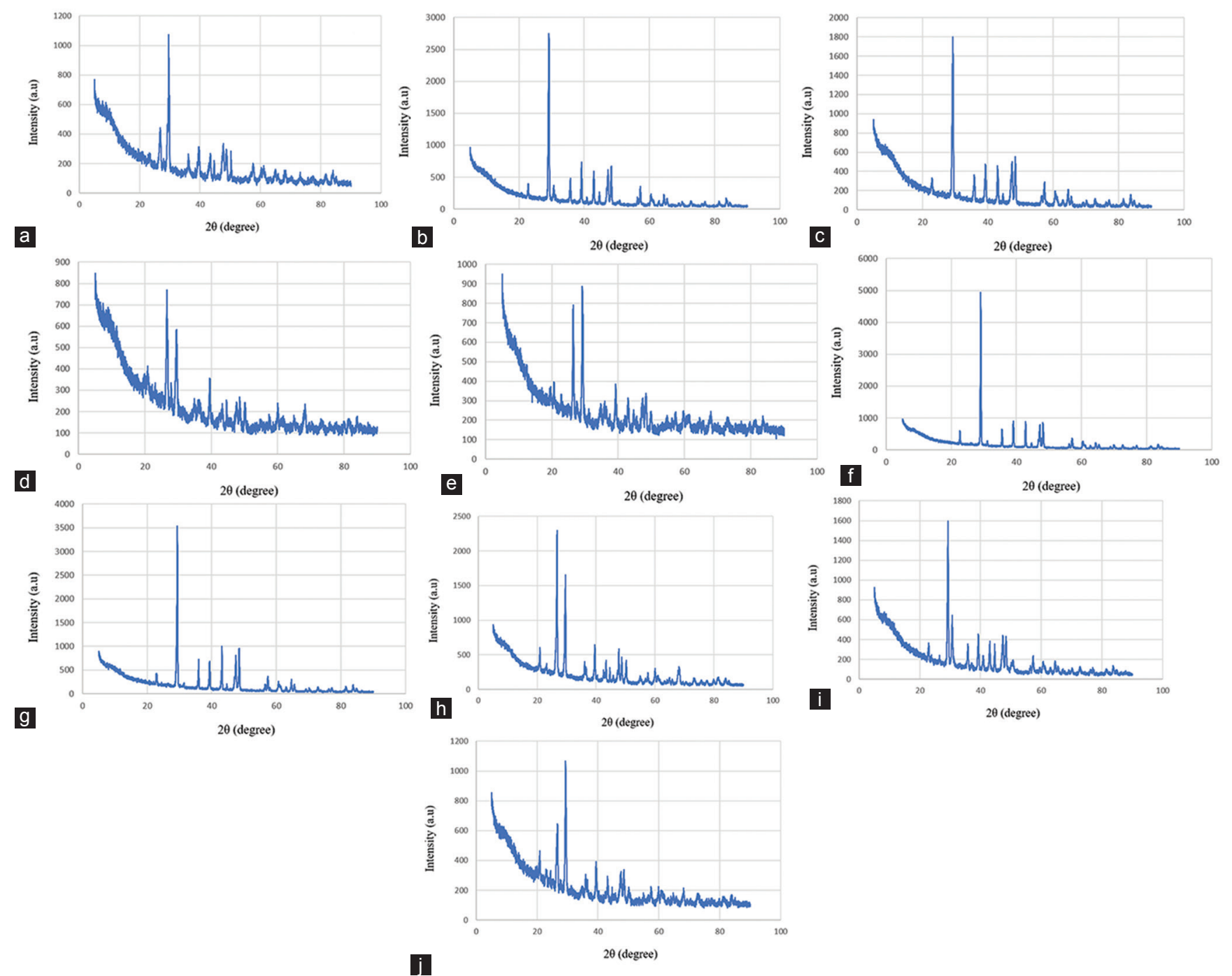

Fig. 3. X-ray diffraction data of the ten different rocks collected from Haybat Sultan place that represented by a-j.

in the XRD data in terms of crystallinity for the majority of the rock samples, although a minor difference can also be seen in these spectra, which could be due the origin place of rocks.

The average crystalline grain size of the powder rock samples was determined using Debye-Scherrer equation (Birks, 1964):

$$
D=\frac{0.9}{\beta \cos \theta}
$$

where $\mathrm{D}, \lambda, \beta, \theta$, and 0.9 are the particle size in $\mathrm{nm}$, the wavelength of the X-ray, the full width at half maximum, the peak position, and the Scherrer constant, respectively. 

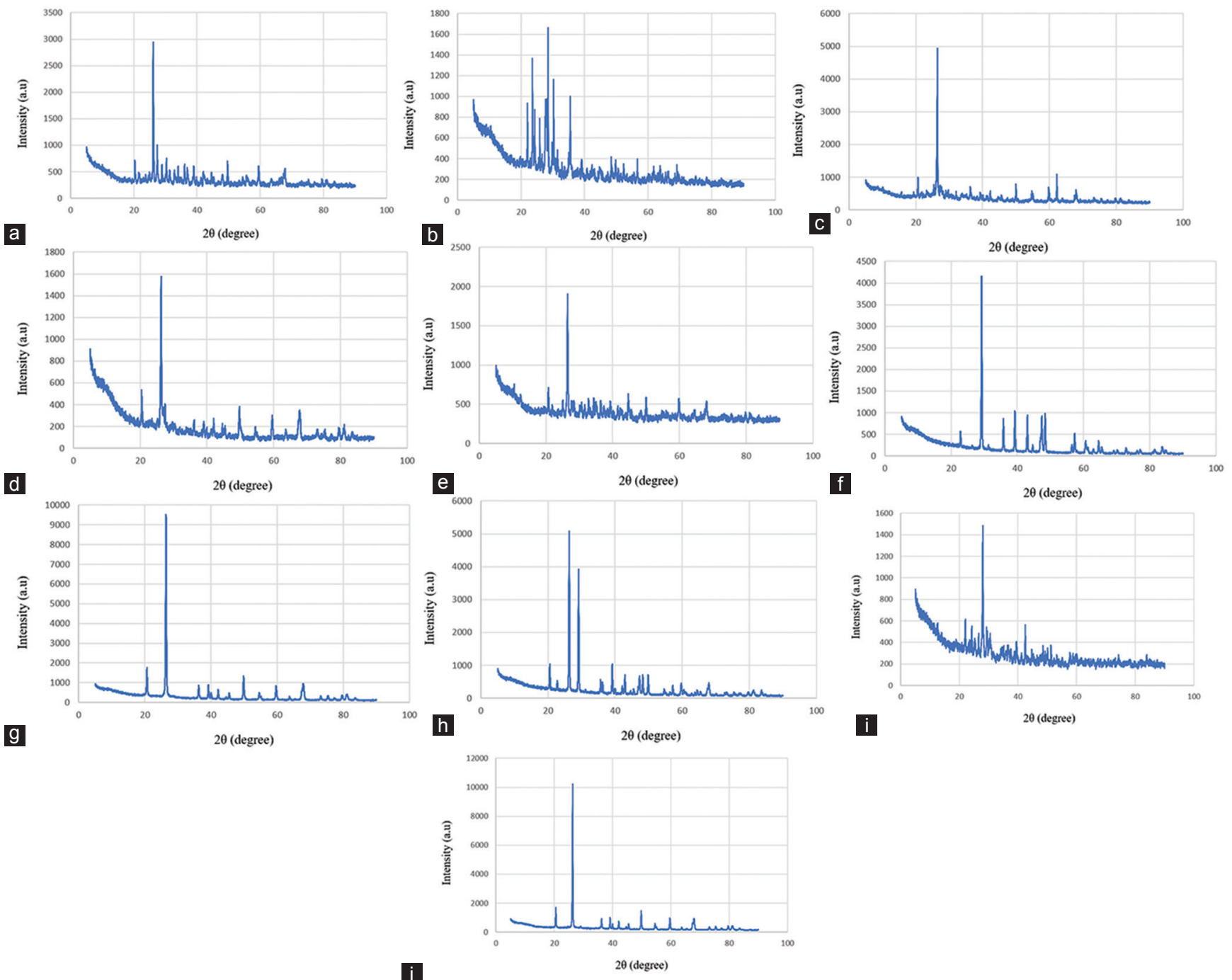

Fig. 4. X-ray diffraction data of the ten different rocks collected from TaqTaq place that represented by a-j.

Using this equation, the crystalline grain size (D) for the collected rocks was found to be as summarized in Table IV:

\section{The Rocks Appearance}

Rocks on earth can appear with endless array of colors, started from shiny bright and ended with dull dark. The variety of their colors is a result of number of factors. First, the mineral those build up the rocks. Some rock consists only one type of mineral (for example, gold $[\mathrm{Au}]$ and silver $[\mathrm{Ag}]$ ), whereas the majority are consisting of different types of mineral bound together such as ferric oxide $\left(\mathrm{Fe}_{2} \mathrm{O}_{3}\right)$ and $\mathrm{CaCo}_{3}$. Each type of mineral has its chemical composition that determined their unique color. Next factor is the impurities that interact with the minerals and the mineral concentration finally, the atomic bounds within the mineral structure. This factor has observed effect on the absorbed and reflected wavelengths to our eyes, for instance, diamond and graphite are both pure carbon but has different color properties (Mishra, Chhalodia and Tiwari, 2018; Breeding, Magana and Shigley, 2018; Tiwari et al., 2016;
TABLE IV

Average Particle Size for the Collected Rocks

\begin{tabular}{lc}
\hline \hline Rocks code & Average particle size $(\mathrm{nm})$ \\
\hline HS & $1-4$ \\
TA & $2-5$ \\
GT & $2-7$ \\
\hline \hline
\end{tabular}

Sheng et al., 2011). The appearance of the rock samples shows a variety of colors, as represented in Fig. 6. Overall, samples collected from HS contain high concentration of lime $(\mathrm{CaO})$, which can be responsible of their light color (for example, number 6 of Fig. 6a), whereas the gradient in color refers to different concentration of the other mineral oxides, for instance, iron oxide lends the red color to the sample with consideration of their concentration. To study this effect, HS6 (Fig. 6a) and TA6 (Fig. 6b) can be taken which have the same concentration of $\mathrm{CaO}$ whereas the ratio of $\mathrm{Fe}_{2} \mathrm{O}_{3}$ exceeds by 4 times in TA6 compare to HS6. Besides, the shiny appearance of the rock samples, especially GT samples (Fig. 6c) is due to the high content of silica $\left(\mathrm{SiO}_{2}\right)$ relative to the other minerals. 

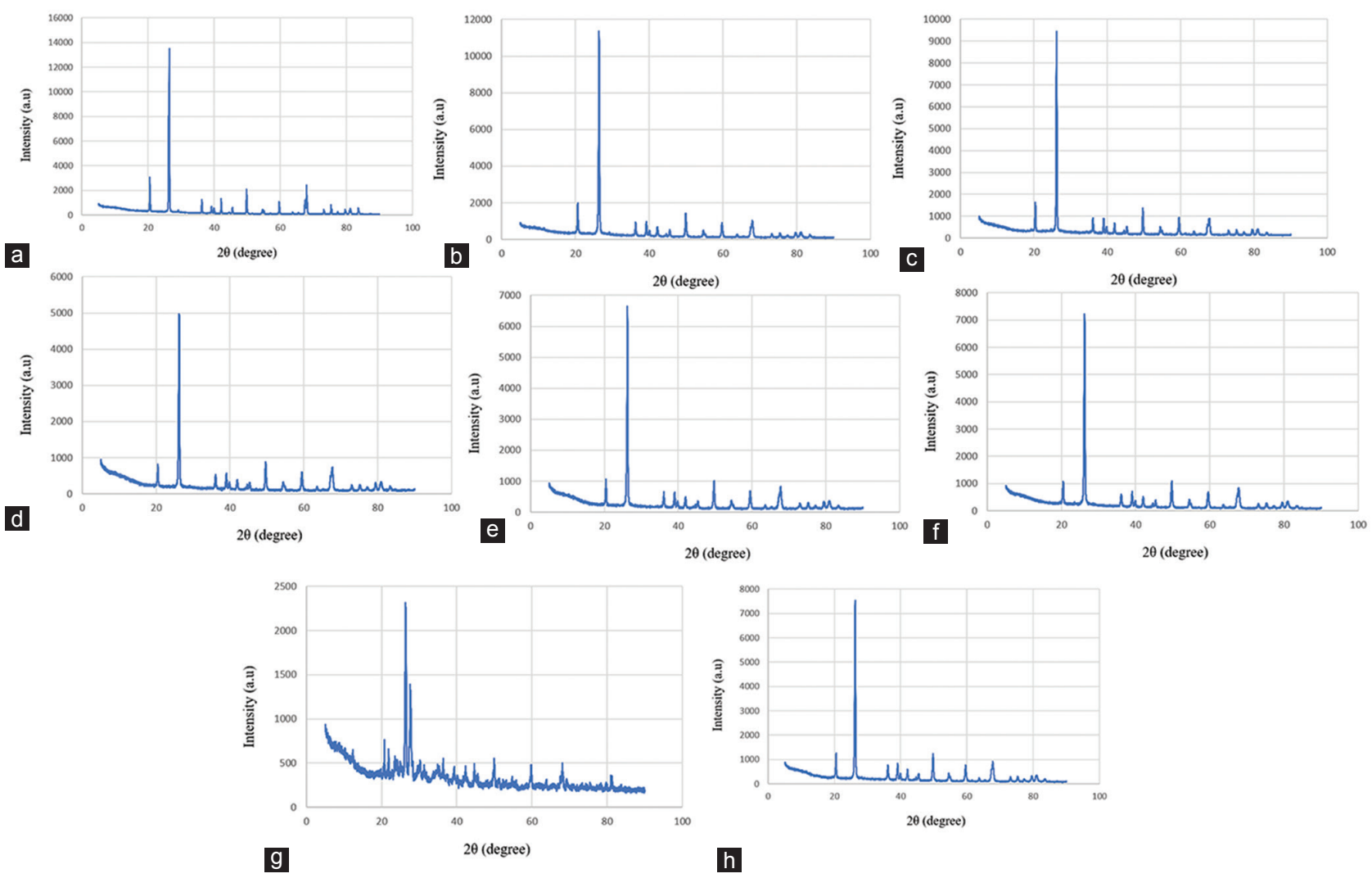

Fig. 5. X-ray diffraction data of the eight different rocks collected from Garmuk place that represented by a-h.

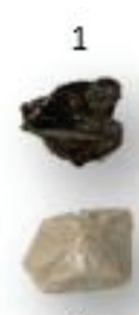

6
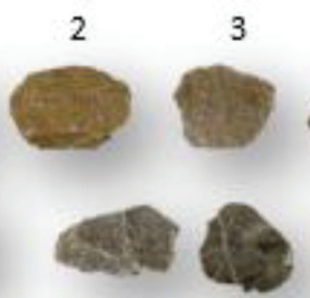

7

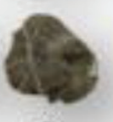

8
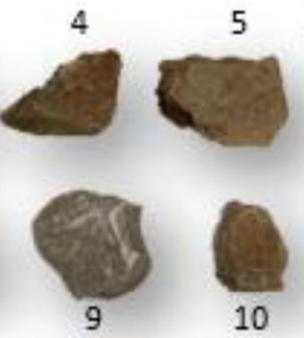

a
6

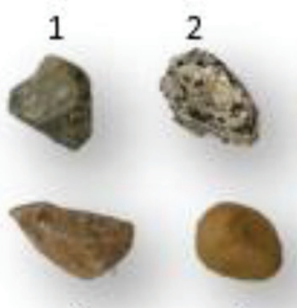

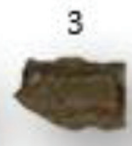

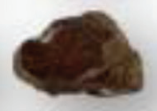

8

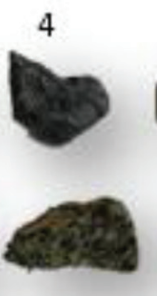

9
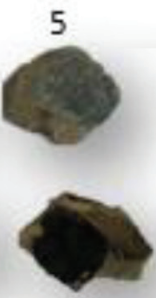

10 b

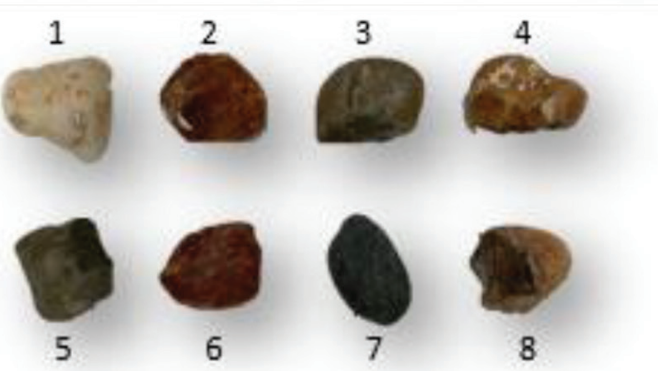

c

Fig. 6. External view (appearance) of the collected rock samples from (a) Haybat Sultan, (b) TaqTaq, and (c) Garmuk.

\section{CONCLUSION}

Twenty-eight samples of different rocks collected from places of Koya city, TA and GT have been analyzed using both XRF and XRD techniques. These two techniques were effective in analyzing the chemical composition and crystalline structure of the collected rocks, as on the one hand, they successfully shown the major and minor minerals in these rocks as well as shown the phases of them, on the other hand. It has been proven from the XRF data that $\mathrm{Ca}-\mathrm{K}^{\alpha}, \mathrm{Fe}-\mathrm{K}^{\alpha}$, and $\mathrm{Si}-$ $\mathrm{K}^{\alpha}$ were of high concentrations in HS, TA, and GT rock samples, respectively. Furthermore, the XRD data shown that the nature of all collected rocks from HS, TA, and GT were crystalline. The appearance of the collected rocks, on the other hand, was also discussed and it has been shown that the differences in the view of these rocks were due to the various minerals of different concentration contain in these rocks, which gave each rock a specific color.

\section{ACKNOWLEDGMENT}

The author would like to thank Assist. Prof Dr. Faten A Ismael and Dr. Khalid N Sediq for their valuable comments during data analysis.

\section{REFERENCES}

Abdullah, B.A., Chaqmaqchee, F.A.I., and Anwer, S.S., 2017. Determination of major and minor elements in kids' milk using XRF technique. Journal of Chemical, Biological and Physical Sciences, 7, pp.593-598. 
Birks, L., 1946. Particle size determination from X-ray Line Broadening. Journal of Applied Physics, 17, pp.687-692.

Breeding, C.M., Magana, S.E., and Shigley, J.E., 2018. Natural-color green diamonds: A beautiful conundrum. Gems and Gemo, 54, pp.2-27.

Chaqmaqchee, F.A.I., and Baker, A.G., 2016. Study and characterization of polyaniline at various doping of $\mathrm{LiCl}$ wt.\% using electrical measurements and XRF analysis. Journal of Research Updates in Polymer Science, 4, pp.188-190.

Cornaby, S., Mena, A.R., Pew, H.K., Moody, P.W., Hughes, T., Stradling, A., Turner, D.C., and Knight, L.V., 2001. An XRD/XRF instrument for the microanalysis of rocks and minerals. Meas. Sci. Technol, 12, pp.676-683.

Faraj, M.G., Chaqmaqchee, F.A.I., and Omar, H.D., 2017. Structural, morphological and electrical properties of $\mathrm{Zn}$ doped $\mathrm{PbS}$ thin films by chemical spray pyrolysis technique. JOAM, 19, pp.421-416.

Faraj, M.G., Kaka, A.K., and Omar, H.D., 2019. Electrical, optical and structural properties of copper oxide thin films deposited on plastic substrate by spray pyrolysis technique, $A R O, 7$, pp.14-18.

Fatah, S.S., and Mohialdeen, I.M.J., 2016. Hydrocarbon generation potential and thermal maturity of Middle Jurassic Sargelu Formation in Miran Field, Sulaimani Area, Kurdistan Region, NE Iraq. Journal of Zankoy Sulaimani, 2, pp.213-228.

Hassan, M.M., Jones, B.G., Buckman, S., Al-Jubory, A.I., and Ismail, S.A., 2015. Source area and tectonic provenance of Paleocene-Eocene red bed clastics from the Kurdistan area NE Iraq: Bulk-rock geochemistry. Journal of African Earth Sciences, 109, pp.68-86.

Hunt, J.M., 1996. Petroleum Geochemistry and Geology. $2^{\text {nd }}$ ed. W.H. Freeman and Company, New York, p.743.

Lopez, J.M.G., Bauluz, B., Nieto, C.F. and Oliete, A.Y., 2005. Factors controlling the trace-element distribution in fine-grained rocks: The Albian kaolinite-rich deposits of the Oliete Basin (NE Spain). Chemical Geology, 214, pp.1-19.

Loubser, M., and Verryn, S., 2008. Combining XRF and XRD analyses and sample preparation to solve mineralogical problems. South African Journal of Geology, 111, pp.229-238.

Marinangeli, L., Pompilio, L., Baliva, A., Billotta, S., Bonanno, G., Domeneghetti, M.C., Fioretti, A.M., Menozzi, O., Nestola, F., Piluso, E., Pondrelli, M., Salvia, V.L., Somma, M.C., Tateo, F., Petrinca, P., Giulio, C.D., and Tangari, A.C., 2015. Development of an ultra-miniaturised XRD/XRF instrument for the in situ mineralogical and chemical analysis of planetary soils and rocks: Implication for archaeometry. Rendiconti Lincei. Scienze Fisiche e Naturali, 26, pp.529-537.

Meenaa, B.I., Omar, K.A.K., Khan, A., Chaqmaqchee, F.A.I., and Alsalihi, E., 2018. Characterization and comparison of clay from Iraq and Iran for bricks production. Clay Research, 37, pp.8-13.
Mirza, T.A., Kalaitzidis, S.P., Mohammed, S.H., Rashid, S.G., and Petrou, X., 2017. Geochemistry and genesis of sulphide ore deposits in Sharosh Village, Qandil Series, Kurdistan Region, NE Iraq. Arabian Journal of Geosciences, 10, pp.428-446.

Mishra, R., Chhalodia, A.K., and Tiwari, S.K., 2018. Recent progress in nanodiamonds: Synthesis, properties and their potential applications. Ver. Funct. Nano, 2, pp.1-23.

Mohammed, T.A.M., 2012. Composition and phase mineral variation of Portland cement in Mass Factory Sulaimani Kurdistan Region NE- Iraq. International Journal of Basic and Applied Sciences, 12, pp.109-118.

Mohialdeen, I.M.J., Hakimi, M.H., and Al-Beyati, F.M., 2015. Biomarker characteristics of certain crude oils and the oil-source rock correlation for the Kurdistan oilfields, Northern Iraq. Arab J Geosci, 8, pp.507-523.

Nayak, P.S., and Singh, B.K., 2007. Instrumental characterization of clay by XRF, XRD and FTIR. Bulletin of Materials Science, 30, pp.235-238.

Roser, B.P., and Korsch, R.J. 1988. Provenance signatures of sandstone-mudstone suites determined using discriminant function analysis of major-element data. Chemical Geology, 67, pp.119-139.

Sanchez, J.S., Romani, J.R.V., Mosquera, D.F., and Alves, C.A., 2008. Study of origin and composition of coatings in a monument built with granitic rocks, by SEM, XRD, XRF and DTA-TGA. X-Ray Spectrom, 37, pp.346-354.

Sarrazin, P., Blake, D., Bish, D., Vaniman, D., and Collins, S., 1998. A miniature $\mathrm{XRD} / \mathrm{XRF}$ instrument for $\mathrm{in}$-situ characterization of Martian soils and rocks. Journal of Physique. IV France, 8, pp.465-470.

Sheng, X.L., Yan, Q.B., Ye, F., Zheng, Q.R., Su, G., 2011. T-carbon: A novel carbon allotrope. Physical Review Letters, 106, pp.155703-5.

Tissot, B.P., and Welte, D.H., 1984. Petroleum Formation and Occurrence. $2^{\text {nd }}$ Springer-Verlag, Berlin, Heidelberg, New York, p.699.

Tiwari, S.K., Kumar, V., Huczko, A., Oraon, R., De Adhikari, A., and Nayak, G.C., 2016. Magical allotropes of carbon: Prospects and applications. Critical Reviews in Solid State and Materials Sciences, 41, pp.257-317.

Vaniman, D., Bish, D. and Chipera, S., 1991. In-situ planetary surface analyses: The potential of X-ray diffraction with simultaneous X-ray fluorescence. Lunar and Planetary Science Conference, 22, pp.1429-1430.

Vaniman, D., Blake, D., Bish, D., Collins, S., Sarrazin, P., Elliot, T., and Chipera, S., 1998. Landed XRD/XRF analyses of prime target in the search for past or present Martian life. Journal of Geophysical Research, 103, pp.31477-31489.

Wadsworth, W.B., and Baird, A.K., 1989. Modal analysis of granitic rocks by X-RAY diffraction. Canadian Minerologist, 27, pp.323-341. 